\title{
Screw-Laminated Timber Deck Plates
}

\author{
Robert WIDMANN \\ Civil Engineer \\ EMPA \\ Duebendorf, Switzerland
}

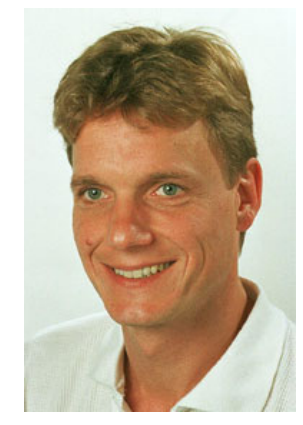

\author{
Robert Widmann, born 1962 , \\ received his civil engineering \\ degree from the College of \\ Engineering of Biberach, \\ Germany \\ 1997 he joined the Wood \\ Department at the Swiss Federal \\ Institute for Materials Testing \\ and Research EMPA as a \\ researcher on wooden \\ constructions.
}

\section{Summary}

Laminated timber in plate action has become quite popular and is applied in various configurations, the oldest being the nail laminated slabs, which are easy to built but have a limited load distributing efficiency: To overcome this draw back, i.e. to improve the stiffness perpendicular to the span but maintaining the ease of fabrication, a screw lamination has been developed with special, connectors arranged in an optimised pattern. Two skew; longitudinal screw laminated deck bridges demonstrate the feasibility of the concept. Tests provide the necessary knowledge of system properties to facilitate a calculation.

Keywords: Timber structures, laminated deck plates, connector, screw, tests, system properties, stiffness, strength

\section{Introduction}

In May 1996 the EMPA Wood department had been consulted by the firm Sauder AG, sawmill and carpentry, in Zihlschlacht in the eastern part of Switzerland, to get assistance for the planning of two small bridges across a creek adjacent to the work site of the firm. The following prerequisites had been formulated: the bridges should carry normal traffic loads, i.e. also the heavy trucks carrying logs to the sawmill. The bridges should be built of timber, allowing the use of the natural resources available at the sawmill and they should be as simple as possible to permit fabrication at the premises with its restricted manufacturing possibilities. Also, the bridges should be finished for service in mid- August, i.e. within a lapse of less than three months.

Ulrich Meierhofer of the EMPA Wood Department immediately worked out various alternatives one of which is based on a new concept: a longitudinal laminated deck bridge with screw fixed timber laminations on edge. This conception promised various advantages and it was therefore decided to implement it.

\section{Laminated Timber Slabs}

\subsection{General}

Laminated timber slabs for bridges and other applications are in fact not new or unusual: Nailed laminated timber slabs had been used in the USA in great quantities decades ago for low duty bridges (of which many are still in operation, [1]). Nail-laminated plates have recently become relatively popular as slabs in residential and office buildings. Laterally prestressed timber slabs were developed in Canada in the 80ies, have been optimised since then and are now used quite frequently. The prestressing is mostly applied to rough sawn boards but sometimes also with glued laminations.

If the concentrated loads, resp. the (tensile) stresses perpendicular to the grain are not too high, glued laminated elements are also used as slabs without prestressing.

All the above mentioned construction methods have their advantages and disadvantages. 


\subsection{Screw-Laminated Slabs}

An important point of distinction is certainly the level of technology required for manufacture. Nailed laminated slabs may be fabricated with the simplest means. By using screw connectors instead of nails it was imperative, that the fabrication process should be just as easy. This meant also, that the size of the screws should allow an installation without predrilling.

In spite of the resemblance of the screw lamination with the nail lamination (connection of two adjacent boards by pin- like metal connectors), the special arrangement of the screws (Fig, 1) causes a completely different action:

Firstly, those screwed connectors arranged at $45^{\circ}$ to the shear plane loaded axially represent a much more efficient (stronger and stiffer) transfer of the shear loads between two adjacent boards than the nails loaded in a bearing- or withdrawal mode. Secondly, the screwed connectors placed at the top and the bottom and parallel to the slab plane allow the transmittance of tensile forces and therefore the build-up of bending moments perpendicular to the span. Thus, a considerably good lateral distribution of concentrated loads, resp. a load sharing between the boards and a higher carrying efficiency can be achieved.
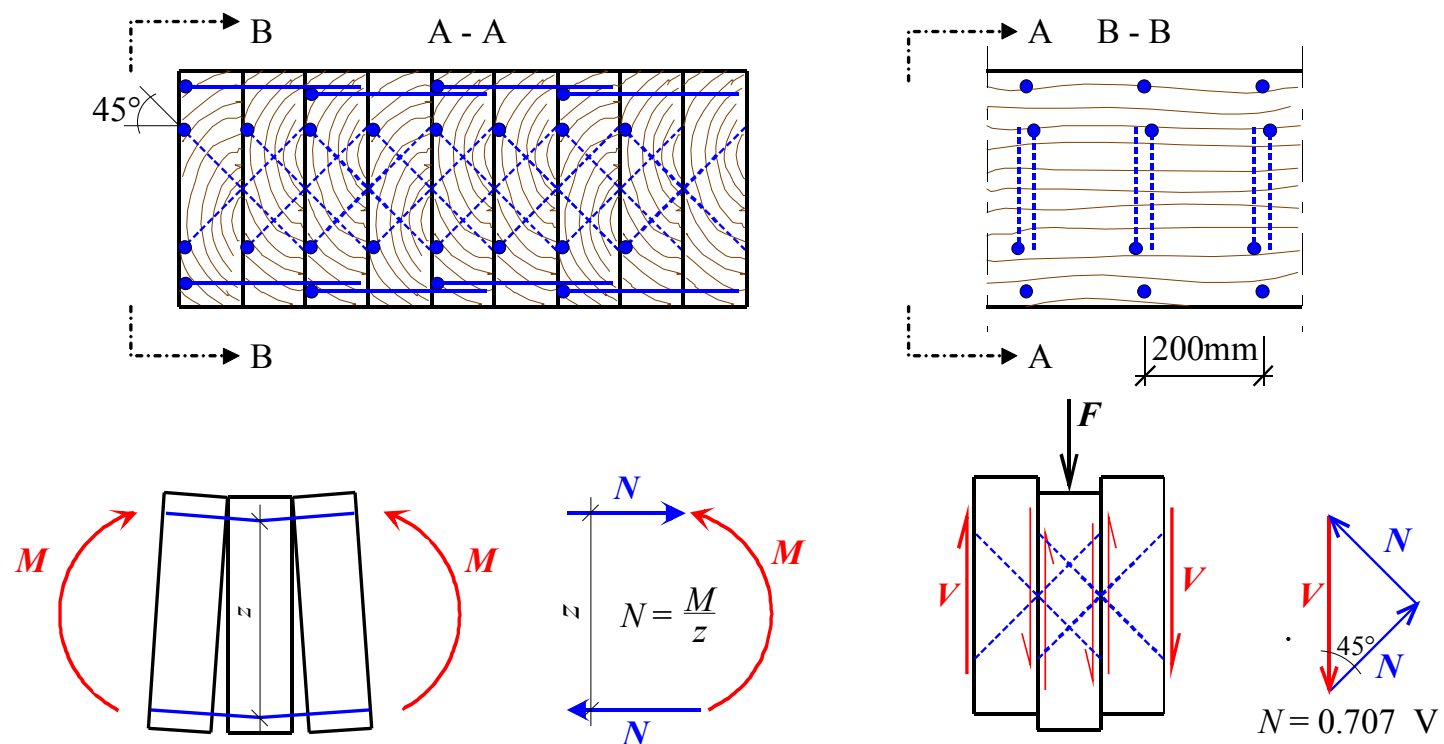

Fig. 1 Arrangement of connectors and assumed transfer of transverse bending and shear loads

Undeniably, the prestressed, glued laminated or both, glued laminated and prestressed slabs have an even better lateral distribution of the concentrated loads. On the other hand, these types of construction require a much more elaborate manufacturing technology, which may not always be available and which also has an economical impact.

For both, the glued laminated and the prestressed construction, it is indispensable to use dried timber, a prerequisite being advantageous but not necessary for screw lamination. The opening of the joints due to shrinking does not harm the functioning of the plate action due to the specific arrangement of the connectors. For the prestressed decks drying of the timber means shrinking and loss of prestress (in addition to the high creep having the same effect).

\section{The Bridges in Zihlschlacht}

\subsection{Particularities}

The two bridges in Zihlschlacht have a skew angle of $60^{\circ}$ and are spanned by CCF- pressure treated fir boards of $6 \mathrm{~cm}$ thickness, $24 \mathrm{~cm}$, resp. $28 \mathrm{~cm}$ depth and a length of $3.5 \mathrm{~m}$ and $5 \mathrm{~m}$ respectively. The rough sawn boards had been air dried after impregnation before assembly and had a moisture content level varying considerably but averaging 22\%; which dropped - as assumed - slowly to about $18 \%$ during service. The slabs were assembled at the workshop close to the bridge sites, transported by truck and positioned to the prepared abutments using the truck's crane (Fig. 2). 
The pin-like screws $\varnothing 7-170$ were prototypes with two special features: no head and a thread that covered the whole length of the screw. They were made of high-strength steel and provided with a high quality corrosion resistant coating, which was tested in a 2600 -hour salt spray test.

Even though the pressure treatment of the boards would have offered enough protection against fungal attack, the bridge decks were covered with fibre reinforced bituminous felt as an impermeable layer. As wearing surface poured asphalt was used on the small bridge and on the bigger bridge a very elastic so called micro pavement of only a few $\mathrm{mm}$ thickness, which proved, however, to be less suitable as cracks developed within a few months.

\subsection{Load Tests and Inspections}

Due to the extremely short period between the first notice and the putting into service of the bridges, the design of the two bridges had been based on a rough, conservative static calculation only. It had been clear from the beginning, however, that more detailed evaluation should follow, if the concept proved to be feasible during manufacture.

The first corresponding activity was a load test with a heavily loaded truck with axle loads of 12 tons (Fig. 3) The maximum deflection at midspan with the truck being placed in the most unfavourable position was $9 \mathrm{~mm}$, i.e. $1 / 550$ of the span.

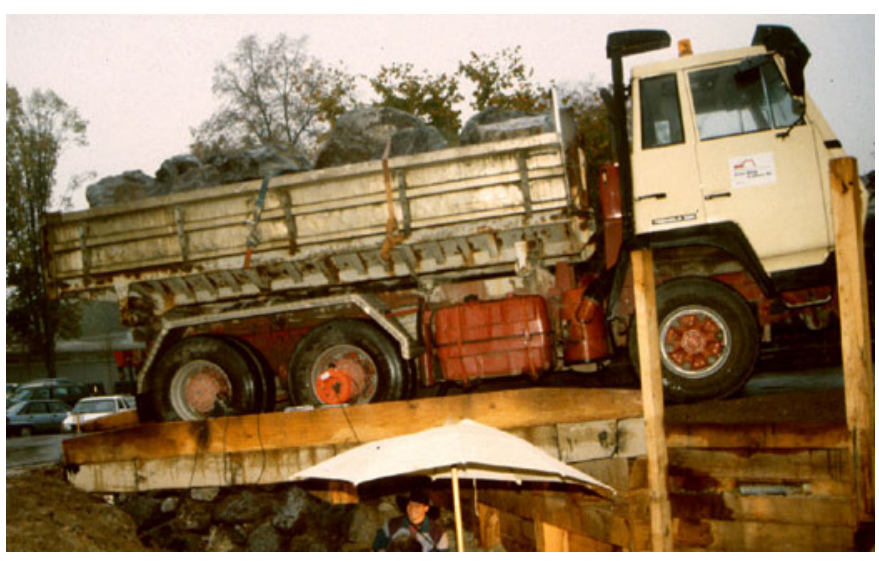

Fig. 2 Load test and measurement of deflection

A second measure to obtain more information on the behaviour of this new type of construction under service condition was to implement a supervision program consisting of periodical checks of the moisture content changes, the development of the joint widths between the individual laminations, the width of the whole bridges (representing the overall shrinking and swelling displacements), the corrosion of the screw connectors and of course also the monitoring of all kinds of visual phenomena indicating any influences and changes of the structure. A third step consists of finding an approach to model the behaviour of the structure by appropriate static means.

\section{Design of a Screw-laminated Timber Slab}

\subsection{General}

To take advantage of the load distributing properties of a laminated timber slab in plate action -and of course especially of the screw laminated slabs -a differentiating design is required taking into account the two- way carrying or load distributing capacity. Statically the behaviour may be approximated by an orthotropic plate and described by the respective differential equations. For practical purposes the design may be performed by the Finite Element Method or by the analysis of a grillage and the assistance of suitable computer programs, a method, which has been tried out in a degree dissertation [2] with system property values established in the research program mentioned in the next paragraph.

In any case, the (geometric and material) system properties are needed to work out deformations, stresses etc. While these properties are known with sufficient accuracy in the direction of the span, no information has been available to start with for the properties in the transverse direction, perpendicular to the span - particularly the bending and the shear stiffness $E I_{90}$ and $G A_{0}$. Another factor, which does have an influence on the behaviour of the system, is the drill-moment and the respective stiffness along the longitudinal axis of the laminations, but this was not taken into account in this study.

The above mentioned stiffness-values are, however, not easy to obtain, as the load carrying action of the screw/ board systems is of high complexity and not readily accessible by analytical means. This meant, that these property values had to be obtained by appropriate tests. Consequently a comprehensive test program was established and carried out in a degree dissertation [3]. 


\subsection{Performed Tests}

The tests performed encompass withdrawal test of the connectors, shear tests of the lamination connector assembly and bending tests of transversal slab stripes. Tests with whole slabs (two-way action) are in preparation.

Test parameters included the type of connector (nails had of course been included), and also the friction between the laminations, which is very difficult to define, but of great influence on the behaviour.

In contrast to assembling of the bridge decks at Zihlschlacht, however, lower moisture contents of $12 \%$ to $15 \%$ of the used fir boards didn't allow the installation of the connectors - nails as well as the prototype screws - without predrilling. The specimen for bending and shear tests consisted of planed board segments with $6 \mathrm{~cm}$ thickness - same size like in Zihlschlacht - and therefore the arrangement of the screws was based on the same system (Fig. 1).

\subsubsection{Shear Tests}

Three or four board segments, assembled with screws in different patterns as well as with nails, formed the specimen for the shear tests (Fig. 3). These tests were arranged especially to assess the influence of the screws that have been arranged at an angle of $45^{\circ}$ as well as the importance of friction between the lamellas on shear-behaviour.

As expected the shear stiffness as well as the shear strength of the - at least partly obliquely screwed specimen were considerably higher than of the nailed ones, but friction between the lamination proved to have a dominant influence: If friction was excluded (by introducing a gap between the lamination), the stiffness values were reduced to a fraction (Tab. 1). This fact has also to be taken into account if one wishes to compare these results with values stated in other papers (see also further below). It can also clearly be seen that arranging the screws at an angle of $45^{\circ}$ has a favourable effect on the transverse shear-behaviour of the system.
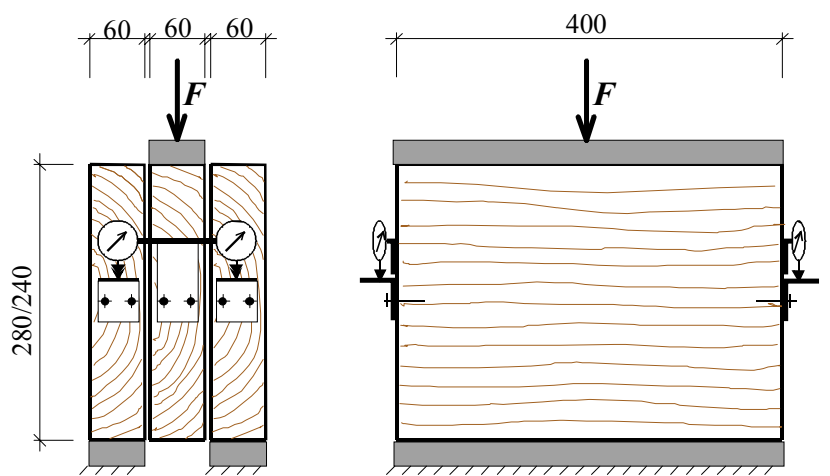

Fig. 3 Shear tests, Types of specimen and testarrangement

Table 1 Results of shear tests

\begin{tabular}{|c|c|c|c|c|c|c|}
\hline Name of Set & Set 1 & Set 2 & Set 3 & Set 4 & Set 5 & Set 6 \\
\hline Number of specimen & 8 & 2 & 4 & 1 & 4 & 4 \\
\hline Type of connector & $\begin{array}{c}\text { Prototype } \\
\text { screw } \\
7-170\end{array}$ & $\begin{array}{c}\text { Prototype } \\
\text { screw } \\
7-170\end{array}$ & $\begin{array}{c}\text { Prototype } \\
\text { screw } \\
7-170\end{array}$ & $\begin{array}{c}\text { Prototype } \\
\text { screw } \\
7-170\end{array}$ & $\begin{array}{l}\text { Nails } \\
6,5-180\end{array}$ & $\begin{array}{c}\text { Prototype } \\
\text { screw } \\
7-170\end{array}$ \\
\hline Number of connectors per joint ${ }^{(1)}$ & $4 *$ h.; $4 * 45^{\circ}$ & $4 * h . ; 4 * 45^{\circ}$ & $4 * 45^{\circ}$ & $4 * h$. & $8 * h$. & $4 *$ h.; $4 * 45^{\circ}$ \\
\hline Friction between the laminations & no & yes & no & no & no & no \\
\hline Cross-sections of specimen & & & & & & \\
\hline Mean ult. or max. load $F_{\mathrm{u}} \quad[\mathrm{kN}]$ & 79.0 & $60.1^{(2)}$ & 69.3 & 20.0 & 47.6 & 96.9 \\
\hline Mean mod. of def. $C_{\mathrm{s}} \quad[\mathrm{kN} / \mathrm{mm}]$ & 92.9 & 467.5 & 58.3 & 12.2 & 26.9 & 120.8 \\
\hline $\begin{array}{l}\text { Remarks } \\
{ }^{(1)} \mathrm{h}=\text { horizontal }\end{array}$ & & $\begin{array}{l}{ }^{(2)} \text { not tested } \\
\text { up to failure }\end{array}$ & & & & \\
\hline
\end{tabular}




\subsubsection{Bending Tests}

The bending tests were performed on four transversal slab stripes (Fig. 4) with a width of $400 \mathrm{~mm}$ and various lengths depending on their thickness of $200 \mathrm{~mm}, 240 \mathrm{~mm}$ and $280 \mathrm{~mm}$ and an arrangement of the screws similar to that one shown in Fig. 1.

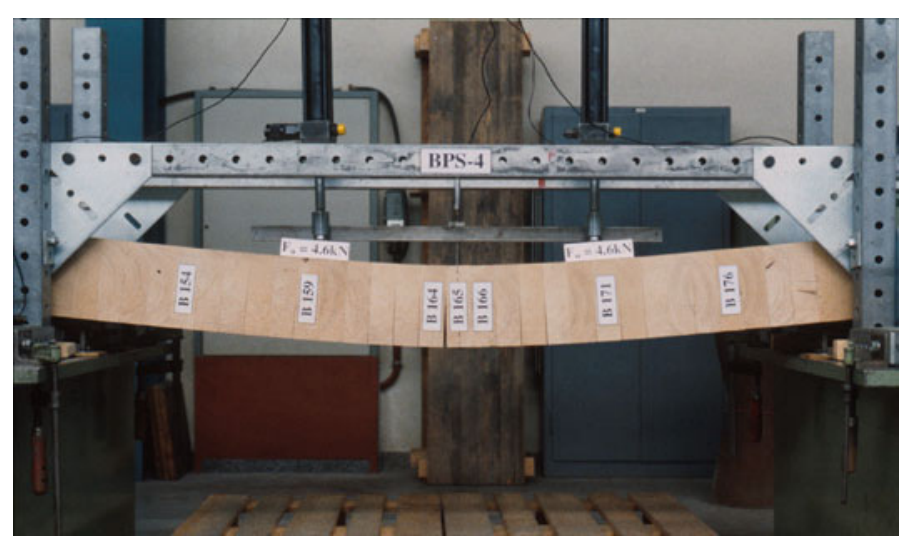

In order to assess the homogeneity of the deflection curve, the deflection of each lamella was recorded; however, bending stiffness was determined in the middle section of the beam - without influence of shear forces and their resulting deflections. No signs of inhomogeneity could have been found and the ultimate loads - failure moments varied from $3 \mathrm{kNm}$ to $4 \mathrm{kNm}$ were in range with calculations performed on base of characteristic values of EC5 and on the assumption that the behaviour as shown in Fig. 1 is true.

Fig. 4 Four-point bending test

The breaking of the specimen had been announced in advance through creaking noises and big deflections, which permits to describe the bending behaviour as 'good natured'.

Determined flexural stiffness $E I$ varied between $0.073 \mathrm{MNm}^{2}$ for the specimen with a thickness of $280 \mathrm{~mm}$ to $0.038 \mathrm{MNm}^{2}$ for the one with a thickness of $200 \mathrm{~mm}$. It could be observed, however, that the beams with smaller thickness proved to have a higher stiffness as well as higher strengths in relation to their thickness. This could be a result of the oblique screws being also involved in the transfer of the bending forces and a possible displacement of the assumed neutral axis.

\subsubsection{Connector-Withdrawal Tests}

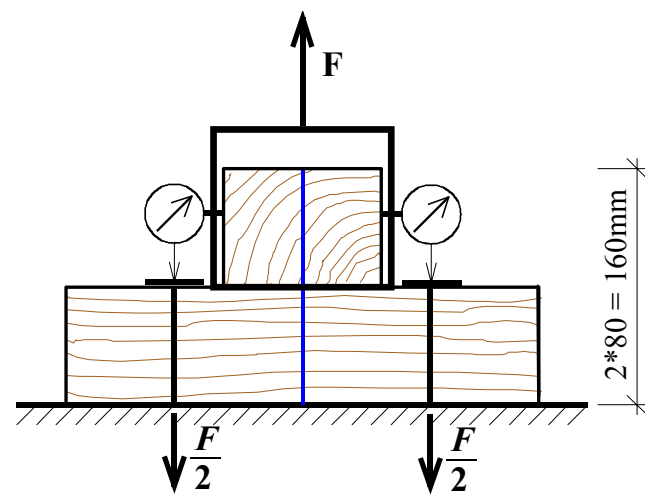

Fig. 5 Connector withdrawal test

Because the assumed static model of the system as shown in Fig. 1 is based on axial loaded connectors, withdrawal tests (Fig. 5) were performed in order to assess the behaviour of the corresponding connector-wood assemblies. This was of interest for the prototype-screws as well as for nails (6.5-180) that were used as a reference.

While nail- and screw assemblies proved to have similar determined moduli of deformation $(\approx 20 \mathrm{kN} / \mathrm{mm})$, there were big differences regarding the ultimate loads. The screw assembly carried about a fivefold withdrawal-load $(\approx 12 \mathrm{kN})$ compared to the corresponding nail-assembly. The effect of these results will be discussed in the next chapter.

\section{Discussion}

Reasons for the implementation of screw-laminated slabs as well as their assumed advantages and disadvantages over other laminated plate-systems were discussed in previous chapters. The two constructed bridge decks are in service since more than four years without the appearance of any major defect so far, which has impressively proved their usefulness.

Another question to be discussed is the performance of the system in comparison with the established nailed or prestressed variants, especially with regard to capability of load sharing as well as economical aspects.

By assuming a longitudinal modulus of elasticity $E_{0 \text {,mean }}$ of $10^{\prime} 000 \mathrm{~N} / \mathrm{mm}^{2}$, and transforming the determined values for shear- and flexural stiffness into moduli $E_{90 \text {,mean }}$ and $G_{0 \text {,mean }}$ their ratio can be compared with material properties of other laminated deck plates according to [4] (Table2) 
Table 2 Material properties of laminated deck plates

\begin{tabular}{|l|c|c|c|c|c|}
\hline System & $\begin{array}{c}\text { Stress- } \\
\text { laminated } \\
\text { sawn } \\
\text { EC5-2 }\end{array}$ & $\begin{array}{c}\text { Stress- } \\
\text { laminated } \\
\text { planed } \\
\text { EC5-2 }\end{array}$ & $\begin{array}{c}\text { Glued- } \\
\text { laminated }\end{array}$ & $\begin{array}{c}\text { Nail- } \\
\text { laminated }\end{array}$ & $\begin{array}{c}\text { Screw- } \\
\text { laminated } \\
\text { w. friction } \\
\text { Tests }\end{array}$ \\
\hline $\mathrm{E}_{90 \text {,mean }} / E_{0, \text { mean }}$ & 0.015 & 0.020 & 0.030 & 0 & 0.010 \\
\cline { 2 - 6 } $\mathrm{G}_{0, \text { mean }} / E_{0, \text { mean }}$ & 0.030 & 0.040 & 0.060 & 0.020 & 0.013 \\
\hline
\end{tabular}

Like assumed, glued- and stress-laminated decks provide a higher stiffness and with this a higher load distribution than the screw-laminated slabs while these on the other hand are stiffer than naillaminated plates. The last mentioned comes first of all out of the fact that for the nailed versions no bending stiffness perpendicular to the laminations can be taken into account.

The results of the withdrawal tests would assume that nail-laminated plates could have a similar flexural stiffness perpendicular to the laminations as the screwed ones. In fact, if loading a nailed deck, it will initially provide also this bending stiffness but as a result bending moments perpendicular to span will build up. These bending moments will lead to axial loading of the nails and with this to nail withdrawing out of the laminations. Even if screw assemblies can carry much higher axial loads than nails, a study [2] on base of system analyses proved that withdrawal of the horizontal screws in the tensile sector is also the limiting factor for the screw-laminated system.

This leads to the last point of the discussion: economical aspects of screw-laminated slabs. As a large number of screws are required to assemble these plates, their availability, prize and installation-time will be the main factors that have to be considered. The producer of the used prototype screws - only a limited number of them were available - decided not to manufacture this type in series, but a similar model was launched recently. The ability to install these screws - as promised - without predrilling even in dry wood as well as providing a semi-automated means of installation could help to compensate the prize that has to be paid for a 'high-tech' screw like this.

\section{Conclusions}

With the development of screw-laminated timber deck plates another competitive variant has been added to the existing plates of similar construction. While the two realised bridge decks proved to be up to the demands of regular service, comprehensive tests - performed to achieve system properties - provide the ability to calculate such laminated plates and to compare with competing systems. Market acceptance will depend on the availability of suitable screws at reasonable prizes.

The introduction of a new screw will allow continuing the test program, especially with regard to confirming the so far determined system properties by tests of whole slabs.

\section{References}

[1] Meierhofer U.,"Entwicklungen im US-amerikanischen Holzbrückenbau", ("Developments in US timber bridge construction") Forschungs- und Arbeitsbericht 115/33, EMPA Wood Department, Duebendorf, 1994, 47pp.

[2] Rauscher B.,"Berechnung von Brückenplatten aus hochkant nebeneinandergestellten Brettern, die miteinander verschraubt werden", ("Calculation of bridge decks made of screw connected vertical laminations") Diplomarbeit, Technisch Universität München, 1997, 65pp.

[3] Widmann R., "Geschraubte Brettstapelbrücke; Ermittlung von Steifigkeits- und Festigkeitswerten anhand von Versuchen", ("Screw-laminated bridge deck; establishing stiffness and resistance values by tests") Diplomarbeit, Fachhochschule Biberach und EMPA Abteilung Holz, 1997, 100pp.

[4] ENV 1995-2,"Eurocode 5: Design of timber structures - Part 2: Bridges”, 1997, 45pp. 